\title{
Serum vascular endothelial growth factor: a prognostic factor in cervical cancer
}

\author{
Petra L. M. Zusterzeel • Paul N. Span • \\ Marja G. K. Dijksterhuis · Chris M. G. Thomas • \\ Fred C. G. J. Sweep • Leon F. A. G. Massuger
}

Received: 5 February 2008 / Accepted: 16 June 2008 / Published online: 15 July 2008

(C) The Author(s) 2008

\begin{abstract}
Purpose To study pre-treatment serum VEGF of patients with invasive cervical cancer and its possible role as prognostic indicator.

Methods VEGF was measured using ELISA in the largest patient group $(n=167)$ to date.

Reults Serum VEGF was significantly higher in advanced tumor stage $(P=0.01)$, large tumor size (tumors larger than $2 \mathrm{~cm})(P=0.03)$, and the presence of vascular space invasion $(P=0.05)$. Serum VEGF was associated with disease free and overall survival [DFS: Hazard Ratio $(\mathrm{HR})=2.61$; 95\% CI $1.32-5.17 ; P=0.006$; for OS: HR $=2.09 ; 95 \%$ CI 1.54-2.84; $P<0.001$, respectively]. In multivariate Cox regression serum VEGF retained its prognostic value for DFS $(\mathrm{HR}=2.10, P=0.03)$ and $\mathrm{OS}(\mathrm{HR}=1.92, P=0.04)$. Conclusions Serum VEGF levels correlate with more advanced and more aggressive disease in cervical cancer and may be a useful prognostic factor in patients with cervical cancer.
\end{abstract}

Keywords Angiogenesis - VEGF · Vascular endothelial growth factor · Cervical cancer · Prognostic value · Survival

P. L. M. Zusterzeel · M. G. K. Dijksterhuis · C. M. G. Thomas · L. F. A. G. Massuger

Department of Obstetrics and Gynaecology, Radboud University

Nijmegen Medical Centre, Nijmegen, The Netherlands

P. N. Span $(\varangle) \cdot$ C. M. G. Thomas · F. C. G. J. Sweep

Department of Chemical Endocrinology 479,

Radboud University Nijmegen Medical Centre,

PO Box 9101, 6500 HB Nijmegen, The Netherlands

e-mail: p.span@ace.umcn.nl

Present Address:

M. G. K. Dijksterhuis

Department of Obstetrics and Gynaecology,

Ikazia Hospital, Rotterdam, The Netherlands

\section{Introduction}

At present, results of primary surgery on one hand and radiotherapy on the other as the primary treatment modality in low-stage cervical carcinoma are comparable. Many patients with cervical cancer are relatively young. In those cases most gynecologic oncologists prefer surgery as this preserves ovarian function and affects sexual function to a lesser extent than primary radiotherapy. Furthermore, surgery provides information on the presence of positive lymph nodes, which in that case leads to a worse prognosis. The presence of positive lymph nodes will create the necessity of adjuvant radiotherapy. Radiotherapy given in an adjuvant setting leads to a high incidence of severe complications. A prognostic factor that can accurately predict aggressive disease may identify patients with clinical stage IB or IIA in whom radiotherapy should be considered as primary therapy.

Angiogenesis, the formation of new blood vessels from pre-existing capillaries, is essential for both tumor growth and tumor spread (Folkman 1990, 1995). It seems likely that a tumor capable of inducing an extensive angiogenic response will show aggressive behavior and worse prognosis. This implies that quantifying the extent of angiogenesis could serve as an indicator of tumor behavior and prognosis. Among the various angiogenic factors vascular endothelial growth factor (VEGF) has a pivotal role in tumor angiogenesis and is known to participate in neovascularisation by promoting the differentiation of endothelial cells and increasing the permeability of capillaries (Ferrara 1995; Ferrara and Vis-Smyth 1997). Furthermore, tumor associated stroma has also been shown to produce VEGF (Fukumura et al. 1998).

The relationship between tumor or serum VEGF and tumor behavior in cervical cancer has been the focus of a 
number of studies, with conflicting data as result. Cheng et al. showed that intra-tumoral protein levels of VEGF correlated well with local tumor progression and tumor metastasis (Cheng et al. 2000). Furthermore, they found that patients with high protein levels of VEGF had poorer disease-free and overall survival rates. Tissue expression of VEGF was found to be significantly increased in patients with cervical intra-epithelial neoplasia compared to patients with healthy cervices and to be highest in patients with squamous cervical carcinoma (Dobbs et al. 1997). Some studies showed that tumor expression of VEGF was a highly significant and independent prognostic factor in cervical cancer patients treated with primary radiotherapy (Loncaster et al. 2000). Others, however, did not find tissue VEGF expression to be of any prognostic value (Lee et al. 2002; Tjalma et al. 2000). Serum VEGF levels were significantly higher in both patients with cervical intraepithelial neoplasia and cervical cancer compared to healthy controls (Lebrecht et al. 2002; Moon et al. 2000; Bachtiary et al. 2002; Mitsuhashi et al. 2005; Yang et al. 2006; Gadducci et al. 2007). Interestingly, serum VEGF levels often respond to successful treatment (Moon et al. 2000; Mitsuhashi et al. 2005; Yang et al. 2006) and can have a prognostic value (Bachtiary et al. 2002), although this was not confirmed in a larger study (Lebrecht et al. 2002). These results indicate the tumor as source of elevated circulating VEGF levels. Even so, it offers the possibility of an easily obtainable biomarker with possible diagnostic and prognostic potential.

Currently, it is still difficult to predict tumor behavior in patients with cervical cancer and efforts are being made to find prognostic factors that could contribute to customizing patient care. The purposes of the present study were to determine if serum concentration of VEGF is a possible tumor marker for invasive cervical carcinoma, and to determine its role as a prognostic factor in patients with cervical carcinoma, by correlating serum VEGF levels with established prognostic factors and disease outcome in the largest group of patients with cervical carcinoma so far.

\section{Materials and methods}

\section{Patients}

The Institutional Review Board of the Radboud University Nijmegen Medical Centre approved the study. Patients diagnosed with cervical cancer, scheduled to have an examination under anesthesia in combination with radiographic and/or endoscopic techniques to determine tumor-stage had their blood samples taken whilst being admitted for this procedure. Blood samples were obtained by vena puncture and centrifuged at $3,000 \times g$ for $10 \mathrm{~min}$; serum was aliquoted and stored at $-20^{\circ} \mathrm{C}$ until further analysis. From August 1983 until May 2000, serum samples of 167 patients were collected for testing. The case-notes of these patients were carefully reviewed. We also determined the serum VEGF levels in a group of 20 healthy female controls, comprising blood donating volunteers. Women with FIGO stage IB1 and IIA underwent a radical hysterectomy. Adjuvant radiotherapy was given in case of positive lymph nodes or positive resection areas. In women with FIGO stage IB2, chemoradiotherapy was the treatment of choice. Women with advanced stage disease (IIB, III and IVA) were treated with chemoradiotherapy or radiotherapy with hyperthermia. In the only woman with FIGO stage IVB, treatment was only palliative. The median age of patients was 42 years (range 20-90 years). The median duration of follow-up was 2.8 years, ranging from 0.4 to 15.9 years. Most patients (79\%) were diagnosed with stage IB and IIA disease and squamous cell carcinoma was the predominant histological type. Seventy percent of the patients were premenopausal. Among the patients $46 \%$ were smokers. The control group of 20 female healthy blood-donating volunteers had a median age of 37 years (range 19-64; $P=0.67$ ). Eight of the volunteers were smokers $(P=0.71)$.

\section{VEGF measurement}

VEGF levels were determined in sera with a quantitative enzyme-linked immunosorbent assay (ELISA). The details of the assay, including those regarding specificity and performance, have been described previously (Span et al. 2000). This assay is based on the combination of 4 polyclonal antibodies $(\mathrm{Ab})$ raised in four different animal species including duck, chicken, rabbit and goat, which are employed in a sandwich assay format. The assay measures VEGF $_{165}$ and VEGF $_{121}$, the main isoforms of VEGF. There is no cross-reactivity with VEGF $B$, VEGF C, VEGF D, platelet derived growth factor $\mathrm{AB}$ (PDGF $\mathrm{AB}$ ), insulin growth factor type 1 (IGF-1), human growth hormone (hGH), placental growth factor (PlGF), nerve growth factor (NGF), tumor necrosis factor-alpha (TNF-alpha) and transforming growth factor (TGF). The analytical sensitivity for VEGF is $5 \mathrm{pg} / \mathrm{ml}$. For VEGF, the within-run $\mathrm{CV}$ and between-run $\mathrm{CV}$ are found to be 8.7 and $13.4 \%$, respectively.

\section{Statistical analysis}

Serum VEGF concentrations are presented as median values and expressed in $\mu \mathrm{g} / \mathrm{l}$ (interquartile range). Differences in serum VEGF levels between patients and controls, and between clinical subgroups were tested using the MannWhitney U test and the Kruskal-Wallis test, where appropriate. Furthermore, the correlation between serum VEGF 
levels and disease free (DFS) and overall survival (OS) were tested using Cox-univariate regression analyses. Multivariate Cox regression was performed, with only tumor stage and VEGF entered as variables in the analysis due to limited number of events. A two-sided $P$ value below 0.05 was considered statistically significant. The software packages SAS (version 6.12, SAS Institute Inc., Cary, NC) and SPSS (version 12.0.1, SPSS Inc. Chicago, IL) were used for the statistical analyses.

\section{Results}

\section{Descriptive analyses}

Table 1 summarizes descriptive data of our patient group $(n=167)$. The median VEGF levels differed significantly for patients with cervical carcinoma compared to the group of healthy controls: 0.54 (interquartile range $0.28-1.26 \mu \mathrm{g} /$ 1) versus $0.46 \mu \mathrm{g} / \mathrm{l}$ (interquartile range $0.29-0.60 \mu \mathrm{g} / \mathrm{l}$ ) $(P=0.01 ;$ Table 2$)$.

Table 1 Clinical characteristics of patients with cervical cancer $(n=167)$

\begin{tabular}{|c|c|}
\hline Characteristics & Number $(\%)$ or (range) \\
\hline Age (years) (range) & $42(20-90)$ \\
\hline Follow up (years) (range) & $2.8(0.4-15.9)$ \\
\hline \multicolumn{2}{|l|}{ Stage } \\
\hline IB & $100(60 \%)$ \\
\hline IIA & $32(19 \%)$ \\
\hline IIB & $19(11 \%)$ \\
\hline III & $11(7 \%)$ \\
\hline IV & $5(3 \%)$ \\
\hline \multicolumn{2}{|l|}{ Histology } \\
\hline Squamous & $114(68 \%)$ \\
\hline Adeno & $37(22 \%)$ \\
\hline Adenosquamous & $14(8 \%)$ \\
\hline Unknown & $2(1 \%)$ \\
\hline \multicolumn{2}{|l|}{ Grade } \\
\hline I & $3(2 \%)$ \\
\hline II & $81(48 \%)$ \\
\hline III & $61(37 \%)$ \\
\hline Unknown & $22(13 \%)$ \\
\hline \multicolumn{2}{|l|}{ Lymph nodes } \\
\hline Positive & $23(14 \%)$ \\
\hline Negative & $102(61 \%)$ \\
\hline Unknown & $42(25 \%)$ \\
\hline \multicolumn{2}{|l|}{ Recurrence } \\
\hline Yes & $40(24 \%)$ \\
\hline No & $116(69 \%)$ \\
\hline Unknown & $11(7 \%)$ \\
\hline
\end{tabular}

Table 2 Serum VEGF levels in controls and different clinicopathological categories of patients

\begin{tabular}{|c|c|c|c|c|}
\hline & $N$ & $\begin{array}{l}\text { Median } \\
\operatorname{VEGF}(\mu \mathrm{g} / \mathrm{l})\end{array}$ & $\begin{array}{l}\text { Interquartile } \\
\text { range }\end{array}$ & $P$ \\
\hline \multicolumn{5}{|l|}{ Group } \\
\hline Controls & 20 & 0.46 & 0.31 & \multirow[t]{2}{*}{0.01} \\
\hline Patients & 167 & 0.54 & 0.98 & \\
\hline \multicolumn{5}{|l|}{ Stage } \\
\hline IB & 100 & 0.44 & 0.61 & \multirow[t]{4}{*}{0.01} \\
\hline IIA & 32 & 0.63 & 0.72 & \\
\hline IIB & 19 & 0.52 & 0.72 & \\
\hline III/IV & 16 & 1.04 & 1.28 & \\
\hline \multicolumn{5}{|l|}{ Histology } \\
\hline Squamous & 114 & 0.61 & 0.83 & \multirow[t]{3}{*}{0.62} \\
\hline Adeno & 37 & 0.52 & 0.45 & \\
\hline Adenosquamous & 14 & 0.55 & 0.53 & \\
\hline \multicolumn{5}{|l|}{ Grade } \\
\hline $\mathrm{I} / \mathrm{II}$ & 84 & 0.50 & 0.68 & \multirow[t]{2}{*}{0.22} \\
\hline III & 61 & 0.61 & 0.89 & \\
\hline \multicolumn{5}{|l|}{ Lymph nodes } \\
\hline Negative & 102 & 0.51 & 0.61 & \multirow[t]{2}{*}{0.67} \\
\hline Positive & 23 & 0.45 & 1.07 & \\
\hline \multicolumn{5}{|l|}{ VSI } \\
\hline No & 21 & 0.39 & 0.46 & \multirow[t]{2}{*}{0.05} \\
\hline Yes & 81 & 0.50 & 0.73 & \\
\hline \multicolumn{5}{|l|}{ Depth of invasion } \\
\hline$<0.7 \mathrm{~mm}$ & 29 & 0.50 & 0.72 & \multirow[t]{2}{*}{0.77} \\
\hline$\geq 0.7 \mathrm{~mm}$ & 56 & 0.48 & 0.57 & \\
\hline \multicolumn{5}{|l|}{ Tumor size } \\
\hline$\leq 2 \mathrm{~cm}$ & 31 & 0.38 & 0.73 & \multirow[t]{2}{*}{0.03} \\
\hline$>2 \mathrm{~cm}$ & 76 & 0.64 & 1.00 & \\
\hline
\end{tabular}

$V S I$ vascular space invasion; $n$ number, $P$ is for non parametric MannWhitney U or Kruskal-Wallis test, where appropriate

Associations of serum VEGF with clinicopathological characteristics

We correlated the serum VEGF levels to established prognostic factors in cervical carcinoma, i.e. tumor stage, histological subtype, grade, lymph node involvement, vascular space invasion, depth of invasion and tumor size (Table 2) (Kristensen et al. 1999; Nguyen and Averette 1999). Serum VEGF levels were significantly higher in patients with higher tumor stages (1.04 $\mu \mathrm{g} / \mathrm{l}$ for III and IV) as compared to early stage tumors $(0.44 \mu \mathrm{g} / \mathrm{l}$ for IB) $(P=0.01)$. When vascular space invasion was involved higher serum VEGF levels were found as compared to cases with no vascular space invasion ( 0.50 vs. $0.39 \mu \mathrm{g} / \mathrm{l}$, respectively; $P=0.05)$. Patients with tumors larger than $2 \mathrm{~cm}$ also showed markedly raised serum VEGF levels as compared to patients with small tumor size $(0.64$ vs. $0.38 \mu \mathrm{g} / \mathrm{l}$, respectively; 
$P=0.03$ ). VEGF levels did not correlate with histology, grade, lymph node involvement and depth of invasion. As other factors such as age, menopausal status, smoking, exogenous hormone use and parity might also influence serum VEGF levels, we included these in our analyses. None of these factors, however, showed statistically significant differences in serum VEGF levels.

\section{Survival analyses}

Forty women (24\%) showed recurrence of disease. Cox regression analysis showed that tumor stage, positive lymph nodes, tumor size, and serum VEGF levels were all correlated with DFS and OS in univariate analyses (Table 3). For VEGF, this prognostic value was significant when entered as a continuous factor (for DFS: Hazard Ratio $(\mathrm{HR})=2.61 ; 95 \%$ CI $1.32-5.17 ; P=0.006$; for OS: $\mathrm{HR}=2.09 ; 95 \%$ CI $1.54-2.84 ; P<0.001)$, precluding the definition of a subjective cut-off value, and when the patients were dichotomized using the median value of serum VEGF (for DFS: $\mathrm{HR}=2.00$; 95\% CI 1.15-3.50; $P=0.01 ;$ for $\mathrm{OS}: \mathrm{HR}=2.32 ; 95 \%$ CI $1.25-4.30$; $P=0.006$ ) (shown in Fig. 1). Twenty-four women died within 1 year after diagnosis. These patients had significantly higher serum VEGF levels at the time of surgery than women who survived the first year $[1.10 \mu \mathrm{g} / 1$ (inter- quartile range $0.38-5.36 \mu \mathrm{g} / \mathrm{l}$ ) versus $0.61 \mu \mathrm{g} / \mathrm{l}$ (interquartile range $0.21-0.1 .86 \mu \mathrm{g} / \mathrm{l})](P=0.02)$.

Multivariate analysis

To assess whether the prognostic value of serum VEGF was attributable to its strong association with tumor stage, multivariate Cox regression analysis was performed with tumor stage and VEGF as variables in the analysis. After correction for tumor stage, serum VEGF retained its prognostic value for both DFS (HR $=2.10, P=0.031)$ and OS $(\mathrm{HR}=1.92, P=0.047$; Table 4$)$.

To further characterize this prognostic value of serum VEGF, Kaplan-Meier curves were made after stratification for tumor stage (Fig. 2). Interestingly, serum VEGF discriminated between good and poor prognosis mainly in the clinically relevant tumor stage IIA/B patients. However, due to the low number of samples per group these analyses were not significant.

\section{Discussion}

The results of recent studies have suggested that neovascularisation is one of the most important processes in tumor growth and metastasis. VEGF induces the formation of new
Table 3 Univariate Cox regression analysis of disease free and overall survival

$H R$ Hazard ratio; vs versus; VSI vascular space invasion; 95\% CI $95 \%$ confidence interval

\begin{tabular}{|c|c|c|c|c|c|c|}
\hline & \multicolumn{3}{|l|}{ DFS } & \multicolumn{3}{|l|}{ OS } \\
\hline & HR & $95 \% \mathrm{CI}$ & $P$ & HR & $95 \% \mathrm{CI}$ & $P$ \\
\hline \multicolumn{7}{|l|}{ Stage } \\
\hline IIA vs. IB & 1.21 & $0.56-2.58$ & $<0.001$ & 0.94 & $0.38-2.33$ & $<0.001$ \\
\hline IIB vs. IB & 2.26 & $1.01-5.02$ & & 3.23 & $1.36-7.67$ & \\
\hline III/IV vs. IB & 6.50 & $3.20-13.2$ & & 8.05 & $3.80-17.1$ & \\
\hline \multicolumn{7}{|l|}{ Histology } \\
\hline Adeno vs. squamous & 1.71 & $0.94-3.10$ & 0.29 & 1.59 & $0.72-3.55$ & 0.39 \\
\hline Adenosquamous vs. squamous & 1.56 & $0.65-3.74$ & & 1.83 & $0.62-5.40$ & \\
\hline \multicolumn{7}{|l|}{ Grade } \\
\hline III vs. I/II & 1.58 & $0.89-2.79$ & 0.11 & 1.84 & $0.95-3.55$ & 0.07 \\
\hline \multicolumn{7}{|l|}{ Lymph nodes } \\
\hline Positive vs. negative & 1.84 & $1.12-3.02$ & 0.02 & 8.08 & $1.62-40.3$ & 0.005 \\
\hline \multicolumn{7}{|l|}{$V S I$} \\
\hline Yes vs. no & 1.02 & $0.95-1.09$ & 0.59 & 2.80 & $0.66-11.9$ & 0.11 \\
\hline \multicolumn{7}{|l|}{ Depth of invasion } \\
\hline$\geq 0.7$ vs. $<0.7 \mathrm{~mm}$ & 0.86 & $0.32-2.31$ & 0.77 & 0.50 & $0.17-1.50$ & 0.23 \\
\hline \multicolumn{7}{|l|}{ Tumor size } \\
\hline$>2$ vs. $\leq 2 \mathrm{~cm}$ & 4.83 & $1.47-15.8$ & 0.009 & 5.88 & $1.38-24.9$ & 0.002 \\
\hline \multicolumn{7}{|l|}{ Serum VEGF } \\
\hline Continuous (log transformed) & 2.61 & $1.32-5.17$ & 0.006 & 2.09 & $1.54-2.84$ & $<0.001$ \\
\hline \multicolumn{7}{|l|}{ Serum VEGF } \\
\hline$>$ Median vs. $\leq$ median & 2.00 & $1.15-3.50$ & 0.010 & 2.32 & $1.25-4.30$ & 0.006 \\
\hline
\end{tabular}



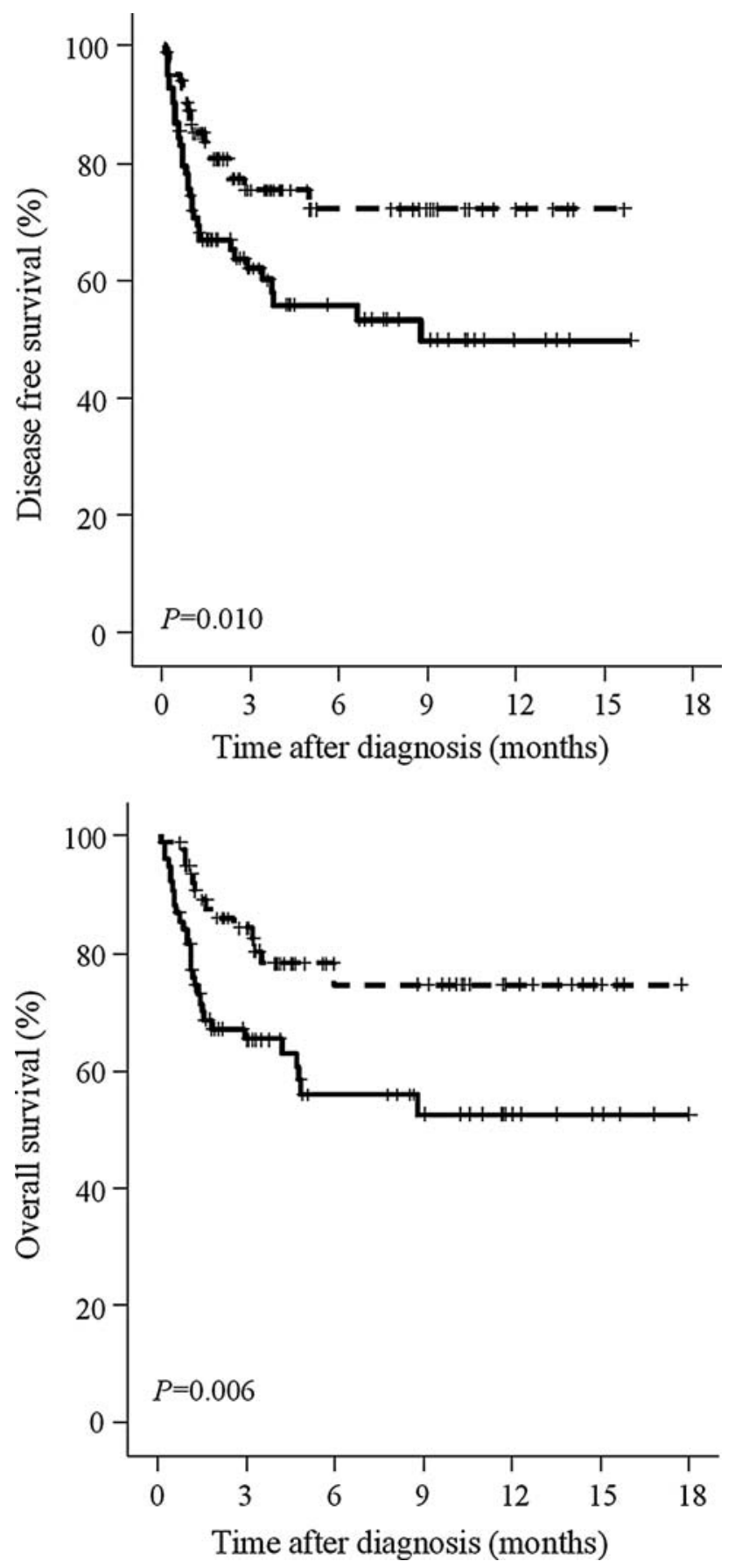

Fig. 1 Kaplan-Meier analysis of serum VEGF concentration. Dashed line indicates $<$ than the median, continuous line indicates $\geq$ than the median. The median serum VEGF concentrations in this study population is $0.54 \mu \mathrm{g} / \mathrm{l}$

capillaries from the pre-existing vasculature. Our results show that serum VEGF levels correlate well with more advanced disease, as levels were significantly raised in patients with higher stages of the disease, in patients with tumors with vascular space invasion and larger tumors. Furthermore, serum VEGF was an independent factor influencing disease-free and overall survival in our study. In a
Table 4 Multivariate Cox regression analysis of disease free and overall survival

\begin{tabular}{|c|c|c|c|c|c|c|}
\hline & \multicolumn{3}{|l|}{ DFS } & \multicolumn{3}{|l|}{ OS } \\
\hline & HR & $95 \% \mathrm{CI}$ & $P$ & HR & $95 \% \mathrm{CI}$ & $P$ \\
\hline \multicolumn{7}{|l|}{ Stage } \\
\hline IIA vs. IB & 1.21 & $0.52-2.80$ & 0.099 & 0.80 & $0.32-2.02$ & $<0.001$ \\
\hline IIB vs. IB & 2.83 & $1.23-6.51$ & & 2.99 & $1.26-7.12$ & \\
\hline III/IV vs. IB & 1.80 & $0.52-6.26$ & & 6.60 & $3.05-14.3$ & \\
\hline \multicolumn{7}{|l|}{ Serum VEGF } \\
\hline $\begin{array}{l}>\text { Median } \\
\quad \text { vs. } \leq \text { median }\end{array}$ & 2.10 & $1.07-4.10$ & 0.03 & 1.92 & $1.01-3.64$ & 0.04 \\
\hline
\end{tabular}

multivariate Cox regression analysis with tumor stage and VEGF as variables in the analysis, serum VEGF retained its prognostic value for both DFS and OS. To further characterize this prognostic value of serum VEGF, Kaplan-Meier curves were made after stratification for tumor stage (Fig. 2). Although the number of events is too small for a meaningful statistical analysis of the Kaplan-Meier curves for serum VEGF in every single tumor stage, these analyses show that the prognostic value of VEGF is particularly discernable in the clinically relevant cohort of patients with stage IIA/B disease.

So far, the relationship between serum VEGF and tumor behavior in cervical cancer has been the focus of a number of studies, but the results remained equivocal (Lebrecht et al. 2002; Moon et al. 2000; Bachtiary et al. 2002; Mitsuhashi et al. 2005; Yang et al. 2006; Gadducci et al. 2007) (Table 5), possibly to the overall low number of patients $(n=23-78)$. To our knowledge, pre-treatment serum VEGF levels of patients with cervical carcinoma have as yet not been reported in such a large patients group $(n=167)$. Almost all studies have found that serum VEGF levels are higher in patients when compared to controls (Lebrecht et al. 2002; Moon et al. 2000; Mitsuhashi et al. 2005; this study; Table 5). Also, a correlation with stage is often found (Lebrecht et al. 2002; Mitsuhashi et al. 2005; this study). Furthermore, the correlation with tumor size we describe here has been reported earlier (Mitsuhashi et al. 2005). However, the relationship between VEGF and recurrence we report here was not found by Lebrecht et al. (2002), whereas the study of Bachtiary et al. (2002), which also found a relation between serum VEGF and prognosis, only entered 23 patients. This number should have been considered too low for meaningful statistical analyses, especially multivariate regression analysis, due to low power and chance of spurious results. The relation between serum VEGF and prognosis we describe here suggests that angiogenesis may be a major mechanism in the pathogenesis of recurrence in cervical cancer. Previous literature 
Fig. 2 Kaplan-Meier curves for DFS (left) and OS (right) of patients dichotomized by the median level of serum VEGF after stratification for tumor stage. Dashed line indicates $<$ than the median, continuous line indicates $\geq$ than the median. The median serum VEGF concentrations in this study population is $0.54 \mu \mathrm{g} / \mathrm{l}$. VEGF discriminates between good and poor prognosis mainly in tumor stage IIA/B patients
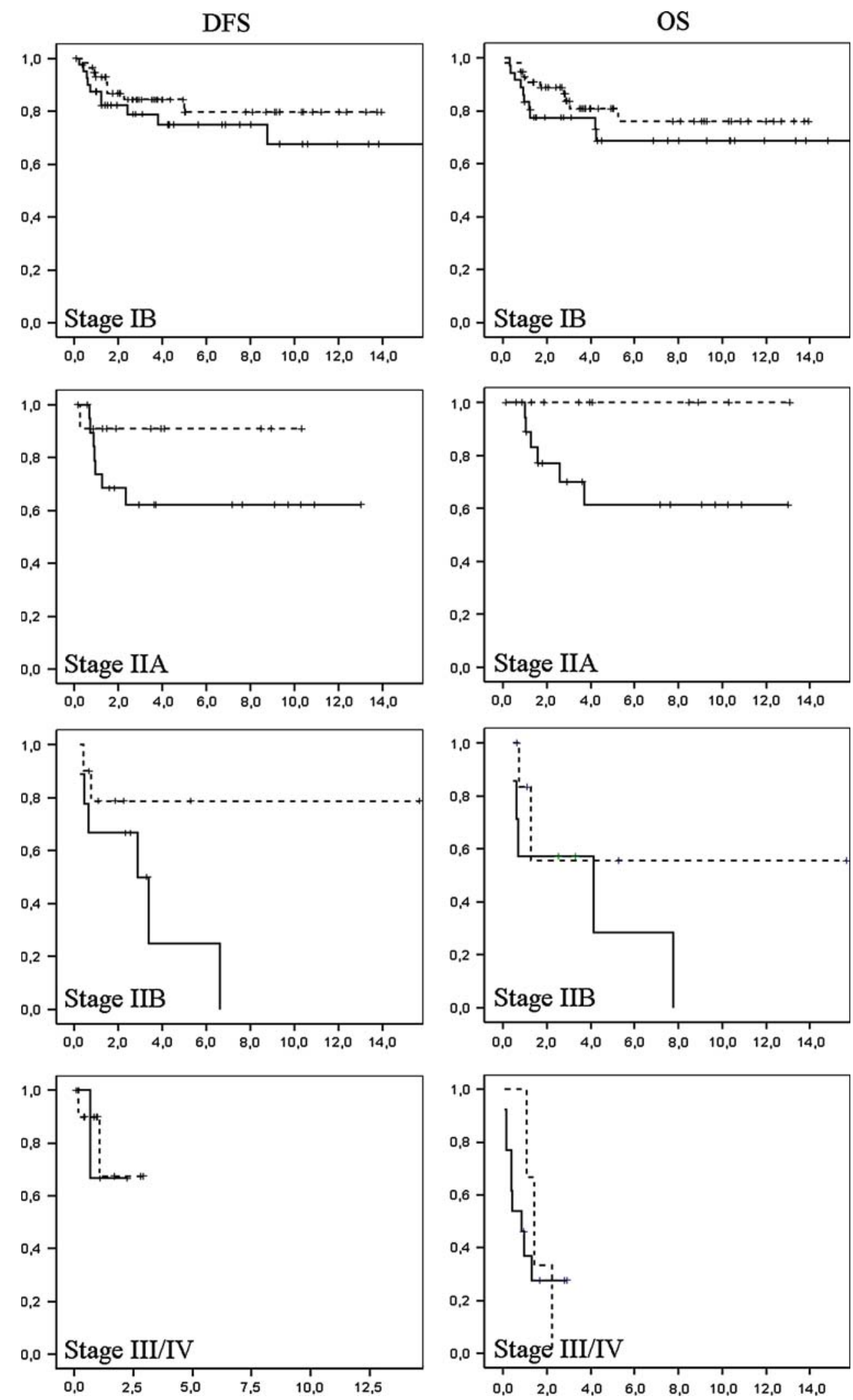

showed that increased angiogenic activity correlated well with prognosis and overall survival in cervical cancer (Cheng et al. 2000; Kaku et al. 1998; Obermair et al. 1998;
Wiggins et al. 1995). Another noticeable result is that in our study serum VEGF levels were not significantly different between patients with squamous cell carcinoma and 
Table 5 Serum VEGF in cervical cancer patients

\begin{tabular}{lllllll}
\hline$N$ & Stage & Treatment & Associations & Prognosis & Multivariate & References \\
\hline 84 & I-IV & Surgery & T/N & DFS - & ND & Lebrecht et al. (2002) \\
& & RT & Stage & OS - & & \\
48 & IIA/IIIA & RT $(n=13)$ & T/N & ND & ND & Moon et al. (2000) \\
& $(n=13)$ & & Treatment effect & & & \\
23 & IB-IV & RT & Grade & PFS + & PFS + & Bachtiary et al. (2002) \\
78 & I-IV & Surgery & T/N & ND & ND & Mitsuhashi et al. (2005) \\
& & RT & Stage & & & \\
& & & Tumor size & & & \\
& & & Treatment effect & & & Yang et al. (2006) \\
42 & ND & ChemoRT & Treatment effect & ND & ND & This study \\
& IB-IV & Surgery & T/N & DFS + & DFS + & \\
& & RT & Stage & OS + & OS + & \\
& & ChemoRT & VSI & & & \\
& & Tumor size & & & \\
\hline
\end{tabular}

those with adeno- or adenosquamous carcinoma, whereas others found adenocarcinoma to be the more angiogenic (Fujimoto et al. 1999) and aggressive subtype (Samlal et al. 1997).

As the range of serum VEGF levels in both patients and controls is very wide, varying from 0.03 to $5.36 \mu \mathrm{g} / \mathrm{l}$, the practical use of VEGF as a tumor marker in individual patients with cervical carcinoma is limited. An explanation for this wide range in VEGF levels might be that angiogenesis in oncology is a dynamic process in which there is a continuous shift of balance between tumor growth, hypoxia, and angiogenesis, involving several inhibitors and promoters of angiogenesis, in which VEGF plays an important role, but is not the only determining factor. From this point of view the serum VEGF level is probably only a snapshot impression of this process and very susceptible to changes. Moreover, serum VEGF levels may also vary intra-individually due to factors such as diet and day- or night-time. Future research should focus on further analyzing the influence of angiogenesis on tumor behavior in cervical cancer. Furthermore, more research is needed to find more about the angiogenic switch that endothelial cells make in cancer tissue, as healthy endothelium is mainly dormant and not susceptible to high serum levels of VEGF (Ferrara 1995).

We conclude that serum VEGF levels are of prognostic value in cervical carcinoma. These findings may lead to future application of therapeutic trials with anti-angiogenic factors. Moreover, its clinical use as a prognostic indicator needs further evaluation. The FIGO classification of cervical cancer, based on clinical staging, is not an accurate way of defining a patient's extend of disease, leading to misclassification in $15-25 \%$ of cases, mostly due to positive lymph nodes, or lymph or blood vessel invasion, possibly resulting in suboptimal care (Lagasse et al. 1980). Patients with positive lymph nodes or lymph or blood vessel invasion need adjuvant radiotherapy leading to a high incidence of complications. Determination of pre-treatment serum VEGF levels may help to improve the selection of the most appropriate therapy regime for an individual patient with low-stage cervical cancer. Perhaps even better might be the combination of VEGF with other markers for lymphogenic of vascular spread of disease in low-stage cervical cancer, such as squamous cell carcinoma antigen (SCC) and CA125 serum levels (Massuger et al. 1997).

Acknowledgments The authors highly appreciate the technical support of Mrs. A.Geurts-Moespot in analyzing VEGF concentrations.

Open Access This article is distributed under the terms of the Creative Commons Attribution Noncommercial License which permits any noncommercial use, distribution, and reproduction in any medium, provided the original author(s) and source are credited.

\section{References}

Bachtiary B, Selzer E, Knocke TH, Pötter R, Obermair A (2002) Serum VEGF levels in patients undergoing primary radiotherapy for cervical cancer: impact on progression-free survival. Cancer Lett 179:197-203. doi:10.1016/S0304-3835(01)00872-2

Cheng WF, Chen CA, Lee CN, Wei LH, Hsieh FJ, Hsieh CY (2000) Vascular endothelial growth factor and prognosis of cervical carcinoma. Obstet Gynecol 96:721-726. doi:10.1016/S00297844(00)01025-5

Dobbs SP, Hewett PW, Johnson IR, Carmichael J, Murray JC (1997) Angiogenesis is associated with vascular endothelial growth factor expression in cervical intraepithelial neoplasia. Br J Cancer $76: 1410-1415$

Ferrara N (1995) The role of vascular endothelial growth factor in pathological angiogenesis. Breast Cancer Res Treat 36:127-137. doi:10.1007/BF00666035

Ferrara N, Vis-Smyth T (1997) The biology of vascular endothelial growth factor. Endocr Rev 18:4-25. doi:10.1210/er.18.1.4

Folkman J (1990) What is the evidence that tumors are angiogenesis dependent? J Natl Cancer Inst 82:4-6. doi:10.1093/jnci/82.1.4 
Folkman J (1995) Angiogenesis in cancer, vascular, rheumatoid and other disease. Nat Med 1:27-31. doi:10.1038/nm0195-27

Fujimoto J, Sakaguchi H, Hirose R, Ichigo S, Tamaya T (1999) Expression of vascular endothelial growth factor (VEGF) and its mRNA in uterine cervical cancers. Br J Cancer 80:827-833. doi:10.1038/sj.bjc.6690428

Fukumura D, Xavier R, Sugiura T, Chen Y, Park EC, Lu N et al (1998) Tumor induction of VEGF promoter activity in stromal cells. Cell 94:715-725. doi:10.1016/S0092-8674(00)81731-6

Gadducci A, Tana R, Cosio S, Genazzani AR (2007) The serum assay of tumour markers in the prognostic evaluation, treatment monitoring and follow-up of patients with cervical cancer: a review of the literature. Crit Rev Oncol Hematol 66(1):10-20

Kaku T, Hirakawa T, Kamura T, Amada S, Kinukawa N, Kobayashi H et al (1998) Angiogenesis in adenocarcinoma of the uterine cervix. Cancer 83:1384-1390 10.1002/(SICI)1097-0142 (19981001)83:7<1384::AID-CNCR16>3.0.CO;2-0

Kristensen GB, Abeler VM, Risberg B, Trop C, Bryne M (1999) Tumor size, depth of invasion, and grading of the invasive tumor front are the main prognostic factors in early squamous cell cervical carcinoma. Gynecol Oncol 74:245-251. doi:10.1006/gyno. 1999.5420

Lagasse LD, Creasman WT, Shingleton HM, Ford JH, Blessing JA (1980) Results and complications of operative staging in cervical cancer: experience of the Gynecologic Oncology Group. Gynecol Oncol 9:90-98. doi:10.1016/0090-8258(80)90013-X

Lebrecht A, Ludwig E, Huber A, Klein M, Schneeberger C, Tempfer $C$ et al (2002) Serum vascular endothelial growth factor and serum leptin in patients with cervical cancer. Gynecol Oncol 85:32 35. doi:10.1006/gyno.2001.6517

Lee IJ, Park KR, Lee KK, Song JS, Lee KG, Lee JY et al (2002) Prognostic value of vascular endothelial growth factor in stage IB carcinoma of the uterine cervix. Int J Radiat Oncol Biol Phys 54:768-779. doi:10.1016/S0360-3016(02)02970-X

Loncaster JA, Cooper RA, Logue JP, Davidson SE, Hunter RD, West CM (2000) Vascular endothelial growth factor (VEGF) expression is a prognostic factor for radiotherapy outcome in advanced carcinoma of the cervix. Br J Cancer 83:620-625. doi:10.1054/ bjoc. 2000.1319

Massuger LF, Koper NP, Thomas CM, Dom KE, Schijf CP (1997) Improvement of clinical staging in cervical cancer with serum squamous cell carcinoma antigen and CA 125 determinations. Gynecol Oncol 64:473-476. doi:10.1006/gyno.1996.4581

Mitsuhashi A, Suzuka K, Yamazawa K, Matsui H, Seki K, Sekiya S (2005) Serum vascular endothelial growth factor (VEGF) and VEGF-C levels as tumor markers in patients with cervical carcinoma. Cancer 103:724-730. doi:10.1002/cncr.20819

Moon HS, Kim SC, Ahn JJ, Woo BH (2000) Concentration of vascular endothelial growth factor (VEGF) and transforming growth factor-beta1 (TGF-beta1) in the serum of patients with cervical cancer: prediction of response. Int J Gynecol Cancer 10:151-156. doi:10.1046/j.1525-1438.2000.00013.x

Nguyen HN, Averette HE (1999) Biology of cervical carcinoma. Semin Surg Oncol 16:212-216 10.1002/(SICI)1098-2388(199904/ 05) 16:3<212::AID-SSU3>3.0.CO;2-B

Obermair A, Wanner C, Bilgi S, Speiser P, Kaider A, Reinthaller A et al (1998) Tumor angiogenesis in stage IB cervical cancer: correlation of microvessel density with survival. Am J Obstet Gynecol 178:314-319. doi:10.1016/S0002-9378(98)80018-5

Samlal RA, van der Velden J, Schilthuis MS, González González D, Ten Kate FJ, Hart AA et al (1997) Identification of high-risk groups among node-positive patients with stage IB and IIA cervical carcinoma. Gynecol Oncol 64:463-467. doi:10.1006/gyno.1996.4576

Span PN, Grebenchtchikov N, Geurts-Moespot J, Westphal JR, Lucassen AM, Sweep CG (2000) EORTC Receptor and Biomarker Study Group Report: a sandwich enzyme-linked immunosorbent assay for vascular endothelial growth factor in blood and tumor tissue extracts. Int J Biol Markers 15:184-191

Tjalma W, Weyler J, Weyn B, Van Marck E, Van Daele A, Van Dam $P$ et al (2000) The association between vascular endothelial growth factor, microvessel density and clinicopathological features in invasive cervical cancer. Eur J Obstet Gynecol Reprod Biol 92:251-257. doi:10.1016/S0301-2115(99)00295-X

Wiggins DL, Granai CO, Steinhoff MM, Calabresi P (1995) Tumor angiogenesis as a prognostic factor in cervical carcinoma. Gynecol Oncol 56:353-356. doi:10.1006/gyno.1995.1062

Yang YC, Wang KL, Su TH, Liao HF, Wu MH, Chen TC et al (2006) Concurrent cisplatin-based chemoradiation for cervical carcinoma: tumor response, toxicity, and serum cytokine profiles. Cancer Invest 24:390-395. doi:10.1080/07357900600705359 